\title{
(2) OPEN ACCESS \\ Academic performance, subsequent socioeconomic status and suicide attempt in adulthood: path analyses on Swedish cohort data
}

\author{
Alma Sörberg Wallin $\mathbb{B}^{1}{ }^{1}$ Kimmo Sorjonen, ${ }^{2}$ Anton Lager, ${ }^{1,3}$ Daniel Falkstedt ${ }^{1}$
}

- Supplemental material is published online only. To view please visit the journal online (http://dx.doi.org/10.1136/ jech-2020-214402)

For numbered affiliations see end of article.

Correspondence to Alma Sörberg Wallin, Department of Global Public Health, Karolinska Institutet, Stockholm SE-171 77 ,

Sweden;

alma.sorberg.wallin@ki.se

Received 4 May 2020

Revised 14 July 2020

Accepted 15 July 2020
Check for updates

(c) Author(s) (or their employer(s)) 2020. Re-use permitted under CC BY. Published by BMJ.

To cite: Sörberg Wallin A, Sorjonen $\mathrm{K}$, Lager A, et al. J Epidemiol Community Health 2020;74:10021007.

\begin{abstract}
Background Poor academic performance in childhood is associated with suicide attempt in adulthood, but the mechanisms are not known. We investigated educational attainment as a possible pathway.
\end{abstract}

Methods We followed two sets of cohorts, born around 1950/1970, respectively, in the Swedish populationrepresentative 'Evaluation Through Follow-up' study for a first suicide attempt in national records up to 2013. Data on grade point average (GPA) at age 13/16 and educational attainment (years of schooling) in adulthood were used. The path models included linear and Cox proportional hazards regressions. A model with matched age range during follow-up was used to compare the cohorts.

Results In the 1970 cohort, the association between GPA and suicide attempt between age 26 and 46 was partly mediated by attained education (total association, $\beta=-0.82$; via education: -0.29 , per SD increase in GPA), but GPA also had a direct path to suicide attempt ( $\beta=$

$-0.53)$. There was no evidence of such a pathway in the 1950 cohort between age 41 and 65. In the age-matched analysis, at age 26-46, the association between GPA and suicide attempt was stronger in the 1970 cohort compared to the 1950 cohort $(\beta=-0.72$ and -0.24 , respectively).

Conclusions Differences in attained education seem to partly explain the associations of academic performance with suicide attempt up to middle age. Furthermore, there is some indication that academic performance may have become more important for young people's mental health than it was in previous generations.

\section{INTRODUCTION}

Suicide rates in Sweden are near the average of highincome countries, and reducing the number of suicides is a governmental goal. ${ }^{1}$ However, the pathways leading up to suicidal behaviour are complex and difficult to map out, and include distal and proximal risk factors both at the individual and the societal level. ${ }^{2}$

One possible hypothesis is that the risk of suicide in adulthood increases as a result of early difficulties in school followed by a weaker educational and socioeconomic status (SES). The association between poor academic performance in childhood or adolescence and suicidal behaviour in adulthood, shown in previous studies, ${ }^{3-7}$ is remarkably strong, with up to fourfold or fivefold risks of suicide ${ }^{3}$ and suicide attempt ${ }^{67}$ for people with the lowest quarter compared to the highest quarter of school grades. In addition, this association seems robust to multivariable adjustment for socioeconomic and demographic factors in childhood. ${ }^{3-6}$ Further, social inequalities in suicidal behaviour are well documented, with higher risks of attempted and completed suicide associated with lower education and income. ${ }^{89}$ We are not aware of any studies examining this hypothetical pathway.

Nor has it been studied whether the association between poor academic performance and later risk of suicidal behaviour has increased over time, though there is some evidence on other mental health outcomes. ${ }^{10}$ The educational and labour market structure in many high-income countries, including Sweden, ${ }^{11}$ has changed over recent decades, and the proportion of jobs with low educational demands has diminished. People with weak academic performance and low level of education may thus have become an increasingly disadvantaged group.

We aimed to investigate pathways from childhood cognitive ability, grade point average (GPA) and SES to subsequent suicide attempt in nationally representative cohorts of Swedish school children. Childhood cognitive ability was included since we have previously found a pathway from lower cognitive ability, measured with an IQ-type test, to the risk of suicide attempt through GPA. ${ }^{7}$ Specifically, we aimed to investigate whether the association of GPA and suicide attempt was, to any extent, mediated by attained education and level of income in adulthood, and to compare the associations of cognitive ability and GPA with suicide attempt between two generations who entered adulthood in the 1970s and the 1990s.

\section{METHODS}

The 'Evaluation Through Follow-up' (ETF) study was initiated in the 1960 s at the University of Gothenburg, with the aim to collect data for longitudinal studies on educational and occupational careers. Statistics Sweden, an administrative agency responsible for official and governmental statistics, ${ }^{12}$ stored the data. The data have been collected in waves, with cohorts of pupils born about 5 years apart, except for a longer gap between the two first and the subsequent cohorts for practical and financial reasons. The cohorts comprise nationally representative samples of about $10 \%$ of the population. More information about the project is found on the ETF website. $^{13}$ 


\section{Procedure}

The four oldest cohorts are included in the present study, with pupils born in 1948, 1952, 1967 and $1972(\mathrm{~N}=9208,8347$, 7562 and 7425, respectively). The two older and the two younger cohorts were pooled to create two larger samples, henceforth labelled 'the 1950 cohort' and 'the 1970 cohort', respectively. The cohort data were linked to national registers and databases, using the personal identification number that every Swedish resident holds, and anonymised by Statistics Sweden. We excluded individuals with a suicide attempt before the start of the follow-up, and those who immigrated to Sweden later than 5 years before the school grades were set, because academic and cognitive test performance in newly immigrated students is likely affected by, for example, unfamiliarity with the language. In the 1950 and 1970 cohorts, respectively, 17555 (80\%) and 14987 (81\%) had complete data and were eligible for follow-up. Most of the exclusions were due to missing IQ scores (11\%; most often due to sickness or other school absence) or incomplete or missing grades $(4 \%)$.

\section{Data}

Details on the variables in the study are presented in online supplemental table S1.

\section{Academic performance}

GPA from the last year of compulsory school was used as a measure of academic performance. In the 1950 cohort, school grades were retrieved from the sixth school year, at age approximately 13. (After that, compulsory 9-year schooling was implemented in Sweden, with no grades given during the sixth school year.) In the 1970 cohort, school grades were retrieved from the ninth school year, at age approximately 16. As these grades were decisive for admission to upper secondary schools, incentives to perform well were strong. Information on school grades were mainly retrieved from the ETF database, but for participants born in 1972, this data was available from the Statistic Sweden's school register.

\section{Other pathway covariates}

Childhood cognitive ability was measured with an IQ-type test administered in the sixth school year, at age about 13 , and registered in the ETF data. The IQ test is described in detail elsewhere ${ }^{1415}$ and has been tested for reliability against the Swedish conscription test of general cognitive ability with a correlation of $0.78 .{ }^{16}$ In short, this paper-and-pencil test consisted of three subtests of verbal ability, spatial ability and induction/reasoning, with a total maximum of 120 points. Information on educational attainment and, for the 1950 cohort, income was obtained from the Longitudinal Integration Database for Health Insurance and Labour Market Studies longitudinal integration database for health insurance and labour market studies. ${ }^{17}$

\section{Confounders}

Parental occupational level, as registered in the National Censuses when the participants were at age 7-13 years, was used as a measure of childhood SES. Information on parents' suicidal behaviour and psychiatric diagnosis was obtained from the National Inpatient Register. ${ }^{18}$

\section{Outcome: suicide attempt}

Information on severe suicide attempts requiring inpatient care (at least one overnight stay at the hospital) was obtained from the
National Inpatient Register. This register covers almost all inpatient psychiatric care since 1973 and is administered by the Swedish National Board of Health and Welfare. ${ }^{18}$ Cases with undetermined intent were included, in accordance with standard procedures in Swedish register-based studies, ${ }^{19}$ to mitigate under-reporting and demographic and temporal variations in the recording of intent.

\section{Statistical analyses}

We used path models to investigate associations between IQ, academic performance, educational attainment, level of income and suicide attempt. The participants were followed from 1 January the year after the recording of educational level up until 31 December 2013, date of suicide attempt, emigration or death due to any cause, whichever came first. The analyses were repeated with a follow-up from age 26 to $41 / 46$ in both cohorts for an age-matched comparison. The timeline is depicted in figure 1 . Since the association between GPA and suicide attempt may differ by sex, ${ }^{7}$ interaction with sex was investigated with an interaction term $(\mathrm{GPA} \times \operatorname{sex})$, but no evidence of an interaction was found at the 0.05 level. Possible non-linear associations of IQ and GPA with suicide attempt were investigated by adding quadratic terms to the regression models $(\mathrm{IQ} \times \mathrm{IQ}$; GPA $\times \mathrm{GPA})$, but no evidence of non-linearity was found at the 0.05 level. Differences in the distribution of covariates by suicide attempt were investigated with t-tests and chi-square tests (table 1).

GPA, grade point average; SEK, Swedish krona; SES, socioeconomic status.

In sensitivity analyses, we repeated the main analysis excluding events with undetermined intent to check if the results were biased due to misclassification. Additionally, we excluded all participants with a psychiatric diagnosis in the inpatient register before age 25 (the start of follow-up in the 1970 cohort) to check for a possible effect of reversed causality. All analyses were conducted with Mplus 7.3 statistical software.

\section{RESULTS}

During follow-up, there were 184 first suicide attempts in inpatient care in the 1950 cohort (90 in women, 94 in men) and 172 in the 1970 cohort (84 in women, 88 in men). Average GPA and IQ were lower in participants with a suicide attempt, and more so in the 1970 cohort than in the 1950 cohort (table 1). Lower educational attainment and having a parent with a psychiatric diagnosis or suicidal behaviour were more common in those with a suicide attempt in both cohorts, but a low SES in childhood was more common in those with a suicide attempt only in the 1950 cohort.

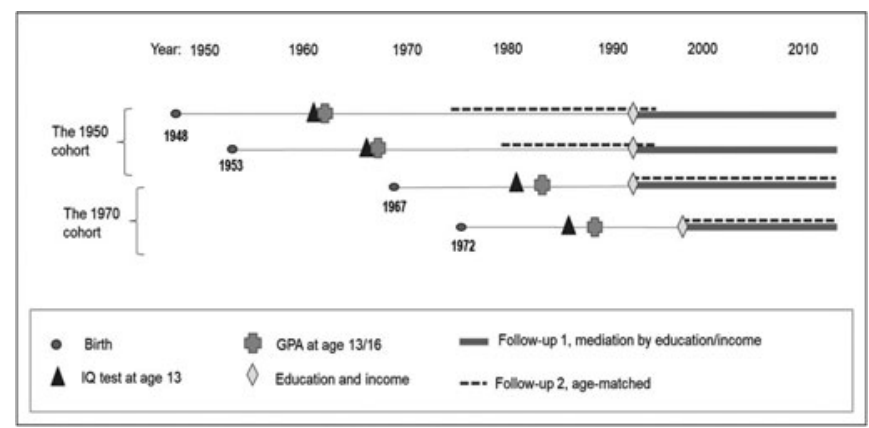

Figure 1 Timeline, with time of measurements and follow-up periods. GPA, grade point average. 
Table 1 Distribution of the covariates in the cohorts, in total and by suicide attempt status

\begin{tabular}{|c|c|c|c|c|}
\hline & Total & No suicide attempt & Suicide attempt & $P$ value \\
\hline \multicolumn{5}{|l|}{ The 1950 cohort } \\
\hline $\mathrm{N}$ & 17555 & 17371 & 184 & \\
\hline GPA, age 13 years. Mean (SD) & $3.18(0.87)$ & $3.18(0.87)$ & $3.06(0.84)$ & 0.06 \\
\hline IQ test score, age 13 years. Mean (SD) & $64.7(17.6)$ & $64.8(17.5)$ & $61.8(18.6)$ & 0.02 \\
\hline Educational level, age 38/43 years. N (\%) & & & & 0.06 \\
\hline Primary and lower secondary, $\leq 9$ years & $3986(22.7)$ & $3939(22.7)$ & $47(25.5)$ & \\
\hline Upper secondary, short track, 10-11 years & $5915(33.7)$ & $5841(33.6)$ & $74(40.2)$ & \\
\hline Upper secondary, long track, 12 years & $2218(12.6)$ & $2196(12.6)$ & $22(12.0)$ & \\
\hline Post secondary, $>12$ years & $5436(31.0)$ & $5395(31.1)$ & $41(22.3)$ & \\
\hline Income* , age 38/43 years. Mean (SD) & $145.3(92.2)$ & $145.4(92.5)$ & $131.3(58.0)$ & $<0.01$ \\
\hline Parent's low SESt, age $7 / 12$ years. N (\%) & $9477(54.0)$ & $9361(53.9)$ & $116(63.0)$ & 0.01 \\
\hline Parents' psychiatric diagnosis or suicidal behaviour, age 20/25-60/65 yearsł. N (\%) & $1991(11.3)$ & $1954(11.2)$ & $37(20.1)$ & $<0.001$ \\
\hline Women, $\mathrm{N}(\%)$ & $8674(49.4)$ & $8584(49.4)$ & $90(48.9)$ & 0.89 \\
\hline \multicolumn{5}{|l|}{ The 1970 cohort } \\
\hline $\mathrm{N}$ & 14987 & 14815 & 172 & \\
\hline GPA, age 16 years. Mean (SD) & $3.27(0.76)$ & $3.28(0.76)$ & $2.68(0.88)$ & $<0.001$ \\
\hline IQ test score, age 13 years. Mean (SD) & $69.6(17.4)$ & $69.7(17.4)$ & $61.2(17.2)$ & $<0.001$ \\
\hline Educational level, age 26 years. $\mathrm{N}(\%)$ & & & & $<0.001$ \\
\hline Primary and lower secondary, $\leq 9$ years & $1787(11.9)$ & $1726(11.7)$ & $61(35.5)$ & \\
\hline Upper secondary, short track, $10-11$ years & $6479(43.2)$ & $6398(43.2)$ & $81(47.1)$ & \\
\hline Upper secondary, long track, 12 years & $4361(29.1)$ & $4341(29.3)$ & $20(11.6)$ & \\
\hline Post secondary, $>12$ years & $2358(15.7)$ & $2348(15.8)$ & $10(5.8)$ & \\
\hline Parent's low SESt, age 13 years. N (\%) & $6194(41.3)$ & $6126(41.3)$ & $68(39.5)$ & 0.63 \\
\hline Parents' psychiatric diagnosis or suicidal behaviour, age 1/6-41/46 yearsł. N (\%) & $2959(19.7)$ & $2908(19.6)$ & $51(29.7)$ & $<0.01$ \\
\hline Women, N (\%) & 7286 (48.6) & 7202 (48.6) & $84(48.8)$ & 0.96 \\
\hline
\end{tabular}

${ }^{*}$ Annual income in 1000 Swedish kronor/SEK.

tManual occupation, farmers or no registered occupation.

¥The participants' age of measurement refers to parents' psychiatric diagnoses and suicide attempts, while parents' death by suicide was measured between participants' age $0 / 4$ years and $60 / 65$ years in the 1950 cohort and 0 years and $41 / 46$ years in the 1970 cohort. Details on age and years of measurements are presented in online supplemental table S1.

GPA, grade point average; SEK, Swedish krona; SES, socioeconomic status.

\section{Path analysis: mediation by education and income}

In the 1950 cohort, there were no clear associations of GPA and education with suicide attempt between age 40/45 and 60/65 (the older age for those with birth year 1948; figure 2 and online supplemental table S2). By contrast, IQ was associated with suicide attempt, mainly through a direct path (online supplemen tal table S2: total association HR $0.85,95 \%$ CI 0.73 to 0.99 ). In the 1970 cohort, GPA was associated with suicide attempt between age 26 and 41/46 (figure 2: $\beta=-.53$ ). Education was also associated with suicide attempt $(\beta=-0.49)$, and about onethird of the association between GPA and suicide attempt was

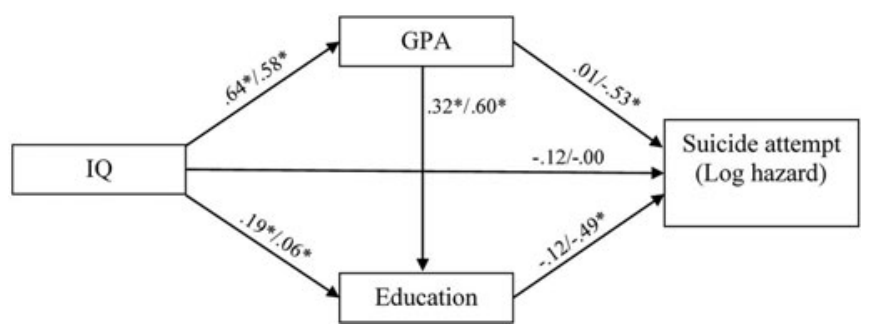

Figure 2 Associations between childhood IQ, GPA, attained educational level and subsequent suicide attempt. For each parameter, the first value is for the 1950 cohort and the second value for the 1970 cohort. The associations are adjusted for sex, childhood socioeconomic position, and parent's psychiatric diagnosis and suicidal behaviour. GPA, grade point average. ${ }^{*} p<0.001, t p<0.05$. mediated by attained education. Taking this pathway into account, the total association corresponded to an approximately halved risk of suicide attempt for each SD increase in GPA (online supplemental table S2: HR $0.44,95 \%$ CI 0.36 to 0.54 ). IQ had only an indirect association, through GPA and education (total association HR $0.60,95 \%$ CI 0.52 to 0.70 ).

Adding income in middle age (available only for the 1950 cohort) to the model did not affect the associations between the other variables (online supplemental figure S1). However, an increase in educational attainment was associated with a higher income $(\beta=0.20)$, which in turn was associated with a reduced risk of suicide attempt (online supplemental figure S2 and supplemental table S3).

Path analysis: the 1950 versus the 1970 cohort at the same age In the age-matched analysis, associations between GPA and suicide attempt were evident in both cohorts, but the association was stronger in the 1970 cohort than in the 1950 cohort $(\beta=$ -0.72 and -24 , respectively; figure 3 ). Furthermore, GPA mediated the association between IQ and suicide attempt in both cohorts; partly in the 1950 cohort and completely in the 1970 cohort (online supplemental table S4).

In sensitivity analyses, the results were very similar to those from the main analysis (online supplemental table S5). Excluding all participants who obtained a psychiatric diagnosis in inpatient care up to age 26 (to check for reverse causality) and all events of self-harm with undetermined intent (to check for misclassification bias) did not affect the associations. 


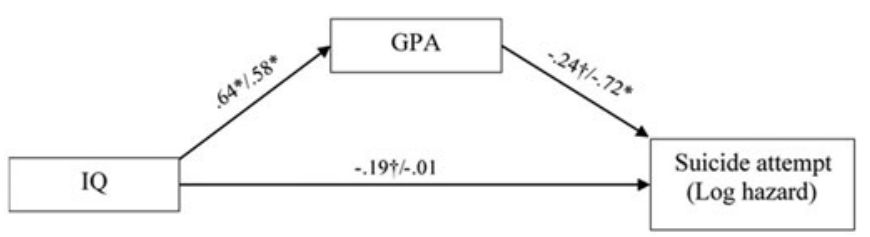

Figure 3 Associations between childhood IQ, GPA and subsequent suicide attempt when restricting the follow-up period to ages 26-41/46. For each parameter, the first value is for the 1950 cohort and the second value for the 1970 cohort. The associations are adjusted for sex, childhood socioeconomic position, and parent's psychiatric diagnosis and suicidal behaviour. GPA, grade point average. ${ }^{*} p<0.001,+p<0.05$.

\section{DISCUSSION}

We followed two nationally representative samples of Swedish women and men for a maximum of 21 years for a pathway analysis of IQ and academic performance (GPA) in adolescence, and SES (education and income) and suicide attempt in adulthood. In the younger sample, born around 1970 and reaching adulthood in the 1990s, there was an indirect path from lower GPA to suicide attempt from age 26 until midlife through lower educational attainment, but also a direct path. In those born around 1950, too, lower GPA was associated with suicide attempt until midlife but not in a later follow-up period up to age 65. In an age-matched analysis, the association between GPA and suicide attempt from age 26 until midlife was stronger in participants born around 1970 compared with those born around 1950 .

\section{Comparison with previous studies}

Previous studies from Sweden ${ }^{5-7}$ and New Zealand ${ }^{20}$ have also shown a strong association between low academic performance and an increased risk of suicide attempt in young adulthood. In line with our findings, previous Swedish studies have found the association between academic performance and suicidal behaviour to be robust when controlling for various background factors, including social and socioeconomic factors. ${ }^{3-6}$

A previous study on the same 1950 cohort as in the present study found an association between academic performance and suicide between age 13 and $55,{ }^{14}$ but we are not aware of any previous studies investigating associations between academic performance and suicide attempt after midlife. Nor are we aware of any study examining the mediating role of attained SES in the association. However, in a survey-based study of the association between GPA and suicide attempt in Swedish adults born between 1969 and 1988, educational attainment and other social factors measured at age 18-33 were found to have only a limited explanatory effect in multivariate adjustment. ${ }^{5}$ In that study, the mediators in adulthood were measured earlier in the life-course as compared to the present study and, furthermore, suicide attempts were self-reported.

We are not aware of any previous studies investigating the associations between academic performance and suicide attempt across generations. However, in a recent Swedish study of associations between academic performance and disability benefits due to mental health disorders in young adulthood, the association increased across graduation years $2000-2007 .{ }^{10}$ Thus, academic performance seems to have increased in importance for mental health outcomes even in recent years.

\section{Interpretation}

There are various possible interpretations of the association between low academic performance and suicide attempts in adulthood. As mentioned earlier, previous studies of the relationship between academic performance and later suicidal behaviour have controlled for circumstances in childhood, such as social and socioeconomic conditions, and found that the association has been left largely unaffected. ${ }^{4-6}$ However, residual confounding is still plausible, such as from early-life mental health problems. For example, externalising problems such as impulsivity, attention deficits and hyperactivity problems, which may hamper learning and performance from an early age, have been commonly mentioned in the literature on academic achievement ${ }^{21} 22$ and may increase the risk of suicidal behaviour. ${ }^{23}$

Cognitive ability has been suggested as a possible confounder in the association between academic performance and subsequent suicidal behaviour. ${ }^{4} 5$ However, the results in this and a previous study, ${ }^{7}$ partly overlapping with the present one, do not support this hypothesis. Instead, cognitive ability seems to operate through academic performance in the pathway to the risk of suicide attempt. ${ }^{7}$

A path from poor academic performance to suicide attempt in adulthood, that is not fully explained by confounding factors, is also possible. In the path analysis, we found support for the hypothesis that a lower SES, in terms of educational level, partly mediated this association in the 1970 cohort. During adolescence, which has been described as a sensitive period in an individual's life, academic success is one essential factor that projects far into adulthood ${ }^{24}$; a social stratification occurs whereby higher-performing students have better access to higher education. Education is a well-established social determinant of health, associated with an increased control over one's life as well as a better socioeconomic situation ${ }^{25}$; therefore, this seems to be a plausible explanation.

If real, the strengthening of the association between the two generations possibly reflects an increased importance of academic performance and educational attainment for well-being and mental health during the past decades. A long-term trend towards more high-educated people in the population ${ }^{1126}$ may have had a negative impact on those who, for various reasons, did not acquire such education. In Sweden, the economic crisis in the 1990s reduced the employment opportunities for low-skilled young people in particular and fuelled the educational trend. ${ }^{11}$ A national expansion of education was encouraged by the government, ${ }^{11}$ and 'over-educated' people competing for jobs with low educational requirements became increasingly common. ${ }^{11} 27$ We could not include attained education and level of income in our age-matched cohort comparison, but this possible explanation should be subject for future investigations, especially since associations of educational attainment and income with suicide seem to have increased over the recent decades. $^{28-30}$

\section{Implications}

Poor academic performance is an important predictor of suicide attempts for a long time after the school years, and possibly even more today than in previous generations. Furthermore, a low level of education in adulthood may contribute to this association, in agreement with known socioeconomic differences in suicide risk on the population level. ${ }^{8} 31$ Thus, interventions targeting the unequal socioeconomic distribution of suicidal behaviour, throughout the life course, are of major public health importance. Additionally, a need for a discussion about the effects of increased educational requirements in society, and the strong emphasis on academic performance, may be indicated. Some scholars argue that formal education has become increasingly 
important on the labour market over the last decades, up to a level where it is necessary in order to be at all employable. ${ }^{26} 32$ However, more research and insight into the mechanisms is needed.

The path to educational inequalities in suicidal behaviour starts early. We could measure cognitive ability in childhood as one characteristic at the beginning of this path, but other characteristics are also affecting academic performance, including conscientiousness, self-efficacy and externalising problems such as impulsivity. ${ }^{21} 2233$ Raising general cognitive ability as a means to reduce the risk of suicidal behaviour is probably not feasible, but other early characteristics and conditions among individuals may possibly be targets for intervention in the school setting. For example, programmes to enhance social and emotional skills have been found to be effective in improving performance and lowering emotional distress in school children. ${ }^{34}$

\section{Strengths and limitations}

The cohorts in this study were nationally representative samples of Swedish women and men, with a high participation rate. Linkage to national registers provided reliable information on school grades and severe suicide attempts, with follow-up throughout middle age.

There are also limitations to our study. First, because information on suicide attempt was obtained from hospital records and not from self-reports, attempts that did not require medical care are not accounted for. Second, we studied individuals with a first suicide attempt after age 26 , and these results may not be generalisable to those with a suicide attempt at a younger age. Third, control of confounding from early psychiatric problems is limited since we had data only on inpatient psychiatric care, and only from 1973 onwards. Furthermore, data on early-life factors such as birth weight and birth order ${ }^{2}$ were not available, but these are generally weak predictors and thus unlikely to act as important confounders in the present study. Fourth, school grades for the 1950 cohort were taken from sixth grade, at age 13, while school grades for the 1970 cohort were taken from ninth grade, at age 16 , which is due to curriculum changes over time. We do not know whether GPA because of this captures academic performance somewhat differently during the different periods and thus influenced the comparison, but it cannot be ruled out. Recent findings by Richard-Devantoy et $a l^{35}$ give some indication that poor academic ability at age 16 better predicts suicide later in life than does poor academic ability in childhood.

\section{CONCLUSION}

Poor academic performance was associated with suicide attempt in adulthood, both in people who were children in the 1950s and in those who were children in the 1970s. Low attained SES, as measured through education, may have contributed to these associations. Furthermore, our study suggests that poor academic performance may have a stronger association with the risk of suicide today than it had in previous generations.

\section{What is already known on this subject}

- Poor academic performance predicts suicidal behaviour in adulthood. Low SES in terms of low educational attainment is a risk factor for suicidal behaviour and might be part of the pathway.

\section{What this study adds}

- We identified a pathway from general cognitive ability and academic performance through educational attainment to the risk of suicide attempt in adulthood in people born around 1970 who were followed to age 46 . We found no evidence of such a pathway in people who were born around 1950 and followed up to age 65. However, an association between academic performance and suicide attempt up to age 46 was found in both cohorts, but this association was much stronger in the younger cohort. Academic performance may have become more important for people's mental health than it was in previous generations.

\section{Author affiliations}

${ }^{1}$ Department of Global Public Health, Karolinska Institutet, Stockholm, Sweden ${ }^{2}$ Department of Clinical Neurosciences, Division of Psychology, Karolinska Institutet, Stockholm, Sweden

${ }^{3}$ Centre for Epidemiology and Community Medicine, Region Stockholm, Stockholm, Sweden

Contributors ASW and DF conceived the study and drafted the first versions of the manuscript, ASW performed the data management and KS performed the statistical analyses. All authors contributed to the design of the study and the interpretation of data, contributed with important intellectual content to the manuscript and have approved the final version to be published.

Funding This study was funded by Forte (grant numbers 2015-00057 and 2017-00173). Competing interests None declared.

Patient consent for publication Not required.

Ethics approval The Regional Ethics Board in Stockholm, Sweden, approved this project. The data were linked and anonymised by Statistics Sweden before granting access for research.

Provenance and peer review Not commissioned; externally peer reviewed.

Data availability statement Data may be obtained from a third party and are not publicly available.

Supplemental material This content has been supplied by the author(s). It has not been vetted by BMJ Publishing Group Limited (BMJ) and may not have been peerreviewed. Any opinions or recommendations discussed are solely those of the author(s) and are not endorsed by BMJ. BMJ disclaims all liability and responsibility arising from any reliance placed on the content. Where the content includes any translated material, BMJ does not warrant the accuracy and reliability of the translations (including but not limited to local regulations, clinical guidelines, terminology, drug names and drug dosages), and is not responsible for any error and/ or omissions arising from translation and adaptation or otherwise.

Open access This is an open access article distributed in accordance with the Creative Commons Attribution 4.0 Unported (CC BY 4.0) license, which permits others to copy, redistribute, remix, transform and build upon this work for any purpose, provided the original work is properly cited, a link to the licence is given, and indication of whether changes were made. See: https://creativecommons.org/licenses/by/4.0/.

ORCID iD

Alma Sörberg Wallin http://orcid.org/0000-0002-8804-095X

\section{REFERENCES}

Socialdepartementet. Prop. 2007/08:110 - En förnyad folkhälsopolitik. Stockholm، 2008. Available http://www.regeringen.se/sb/d/9251/a/100978

2 Gunnell D, Lewis G. Studying suicide from the life course perspective: implications for prevention. Br J Psychiatry 2005;187:206-8.

3 Gunnell D, Lofving S, Gustafsson JE, et al. School performance and risk of suicide in early adulthood: follow-up of two national cohorts of Swedish school children. J Affect Disord 2011;131:104-12.

4 Björkenstam C, Weitoft GR, Hjern A, et al. School grades, parental education and suicide: a national register-based cohort study. J Epidemiol Community Health 2011;65:993-8.

5 Kosidou K, Dalman C, Fredlund P, et al. School performance and the risk of suicide attempts in young adults: a longitudinal population-based study. Psychol Med 2014;44:1235-43.

6 Jablonska B, Lindberg L, Lindblad F, et al. School performance and hospital admissions due to self-inflicted injury: a Swedish national cohort study. Int J Epidemiol 2009;38:1334-41.

7 Sörberg Wallin A, Zeebari Z, Lager A, et al. Suicide attempt predicted by academic performance and childhood IQ: a cohort study of 26000 children. Acta Psychiatr Scand 2018;137:277-86. 
8 Lorant $\mathrm{V}$, Kunst $A E$, Huisman $M$, et al. Socio-economic inequalities in suicide: a European comparative study. Br J Psychiatry 2005;187:49-54.

9 Burrows S, Laflamme L. Socioeconomic disparities and attempted suicide: state of knowledge and implications for research and prevention. Int I Injury Control Safe Promot 2010;17:23-40.

10 Jablonska B, Dalman C, Lundin A, et al. Has the association between low school performance and the risk of disability benefit due to mental disorders become stronger over time? BMC Public Health 2019;19:376.

11 Åberg R. Unemployment persistency, over-education and the employment chances of the less educated. Eur Sociol Rev 2003;19:199-216.

12 Statistics Sweden. About statistics Sweden. 2013

13 University of Gothenburg. ETF - cohort-sequential longitudinal databases evaluation through follow-up. Gothenburg: University of Gothenburg, 2015.

14 Andersson L, Allebeck P, Gustafsson JE, et al. Association of IQ scores and school achievement with suicide in a 40-year follow-up of a Swedish cohort. Acta Psychiatr Scand 2008;118:99-105.

15 Härnqvist K. Relative changes in intelligence from 13 to 18. I. Background and methodology. Scand J Psychol 1968;9:50-64.

16 Härnqvist K. Relative changes in intelligence from 13 to 18. II. Results. Scand J Psychol 1968;9:65-82.

17 Statistics Sweden. Longitudinal integration database for health insurance and labour market studies (LISA by Swedish acronym).

18 Ludvigsson JF, Andersson E, Ekbom A, et al. External review and validation of the Swedish national inpatient register. BMC Public Health 2011;11:450.

19 Niederkrotenthaler T, Wang M, Helgesson M, et al. Labour market marginalisation subsequent to suicide attempt in young migrants and native Swedes. Soc Psychiatry Psychiatr Epidemiol 2017;52:549-58.

20 Fergusson DM, Beautrais AL, Horwood LJ. Vulnerability and resiliency to suicidal behaviours in young people. Psychol Med 2003;33:61-73.

21 Gustafsson J-E, Allodi Westling M, Åkerman A, et al. School, learning and mental health: a systematic review. Stockholm: The Royal Swedish Academy of Sciences, The Health Committee, 2010.

22 Suldo SM, Gormley MJ, DuPaul GJ, et al. The impact of school mental health on student and school-level academic outcomes: current status of the research and future directions. School Ment Health 2014;6:84-98.
23 Hawton K, Saunders KE, O'Connor RC. Self-harm and suicide in adolescents. Lancet 2012;379:2373-82.

24 Viner RM, Ozer EM, Denny $S$, et al. Adolescence and the social determinants of health. Lancet 2012;379:1641-52.

25 Cohen AK, Syme SL. Education: a missed opportunity for public health intervention. Am J Public Health 2013;103:997-1001.

26 Brown P, Hesketh A, Wiliams S. Employability in a knowledge-driven economy. J Educ Work 2003; 16:107-26.

27 Korpi T, Tåhlin M. Educational mismatch, wages, and wage growth: overeducation in Sweden, 1974-2000. Labour Econ 2009;16:183-93.

28 Hiyoshi A, Kondo N, Rostila M. Increasing income-based inequality in suicide mortality among working-age women and men, Sweden, 1990-2007: is there a point of trend change? J Epidemiol Community Health 2018;72:100915.

29 Strand BH, Grøholt E-K, Steingrímsdóttir ÓA, et al. Educational inequalities in mortality over four decades in Norway: prospective study of middle aged men and women followed for cause specific mortality, 1960-2000. BMJ 2010;340:c654.

30 Renard F, Gadeyne S, Devleesschauwer B, et al. Trends in educational inequalities in premature mortality in Belgium between the 1990s and the 2000s: the contribution of specific causes of deaths. J Epidemiol Community Health 2016.

31 Li Z, Page A, Martin G, et al. Attributable risk of psychiatric and socio-economic factors for suicide from individual-level, population-based studies: a systematic review. Soc Sci Med 2011;72:608-16.

$32 \mathrm{Bol}$ T. Has education become more positional? Educational expansion and labour market outcomes, 1985-2007. Acta Sociol 2015;58:105-20.

33 Krapohl E, Rimfeld K, Shakeshaft NG, et al. The high heritability of educational achievement reflects many genetically influenced traits, not just intelligence. Proc Nat Acad Sci U S A 2014;111:15273-8.

34 Durlak JA, Weissberg RP, Dymnicki AB, et al. The impact of enhancing students' social and emotional learning: a meta-analysis of school-based universal interventions. Child Dev 2011;82:405-32.

35 Richard-Devantoy S, Orri M, Bertrand J-A, et al. Childhood cognitive skill trajectories and suicide by mid-adulthood: an investigation of the 1958 British Birth Cohort. Psychol Med 2019;1-8. 